International Journal of Language Education

Volume 5, Number 2, 2021, pp. 51-62

ISSN: 2548-8457 (Print) 2548-8465 (Online)

Doi: https://doi.org/10.26858/ijole.v5i2.16837

\title{
Exploratory and Confirmatory Factor Analysis of PERMA for Chinese University EFL Students in Higher Education
}

\author{
Lan Yang \\ University of Malaya, Malaysia \\ Email:1097772413@qq.com \\ Rashid Bin Saad Mohd \\ University of Malaya, Malaysia \\ Email: pva180091@siswa.um.edu.my
}

Received: 16 December 2020

Reviewed: 3 January 2021-4 March 2021

Accepted: 3 may 2021

\begin{abstract}
The purpose of this research is mainly to explore the validity and reliability of PERMA instruments to determine the nature of PERMA for Chinese university EFL students. A total of 309 Chinese university EFL students from 10 universities in Gansu province were investigated. Selected by cluster random sampling, the extracted data from the survey design underwent exploratory factor analysis(EFA) and confirmatory factor analysis(CFA) with the use of SPSS version 24 and AMOS version 23 to verify the factor structure of the PERMA. The results of EFA indicate similar structures from prior research and the present study. The CFA results testify that the PERMA instrument is satisfactory for Chinese university EFL students. Therefore, this research indicates that the PERMA of Chinese university EFL students also has a five-factor structure, which implies the perceived PERMA in the Chinese university EFL context to be adequately invariant and is an effective measurement tool supporting the research of Chinese university students' well-being. The findings highlight the significance of validating and confirming the PERMA structure and provide new insights into its application across different cultural contexts.
\end{abstract}

Keywords: PERMA, Validity and Reliability, Factor Analysis, Chinese University EFL Students, Higher Education

\section{Introduction}

Chinese EFL university students are facing severe foreign language anxiety in their English learning, which has been a research focus on both second language acquisition and the psychological domain for a long time. In general, traditional psychology focuses on relieving human suffering. Recently, however, with the development of positive psychology in the field of education, research also provides evidence that the university and college students' positive psychology and strengths have a significant influence on their attitudes, behaviors, learning performance, satisfaction, academic achievements, and even on their cognition(Wesson \& Boniwell, 2007). Therefore, more attention should be paid to the emotional element when applying it to the EFL educational field. 


\section{Literature review}

Described as "an umbrella term for the study of positive emotions, positive character traits and institutions that enable individuals to flourish"(M. E. Seligman \& Csikszentmihalyi, 2000), all of which are major concerns in language learning, positive psychology emphasizes the exploration of advantages and values of human psychology as a way to enhance the quality of human life and bring the learners potential to a full realization(Gable \& Haidt, 2005).

With the fast-growing interest over the past twenty years, research scholars have sought to gain a better understanding of the positive psychology constructs(M. E. Seligman \& Csikszentmihalyi, 2000; Snyder \& Lopez, 2009). Seligman explained that well-being is multicomponential and there are several measurable factors and contribute to the development of the well-being conceptual framework which is known as PREMA theory, including five domains, namely positive emotions, engagement, relationship, meaning, and achievement.

According to Seligman(2012), positive emotion refers to experiencing good feelings, such as interest, hope, joy, gratitude(Butler \& Kern, 2016; Cohn \& Fredrickson, 2009; M. E. Seligman, 2012), which is viewed as the main indicator of well-being(Coffey, 2018; Coffey, Warren, \& Gottfried, 2015) and has high correlations with better both physical and mental health and the life satisfaction(Diener, 2000).

Engagement in positive psychology refers to the act of becoming highly interested, absorbed, or focused in daily life activities(Butler \& Kern, 2016; Csikszentmihalyi, Abuhamdeh, \& Nakamura, 1990; M. E. Seligman, 2012)which is the state that the individuals can be fully interested and absorbed in activities and use their curiosity and skills to the inquiry. A high level of engagement in an activity is also referred to as "flow"(Csikszentmihalyi et al., 1990), or the overall feeling of being "in the zone". Engagement can be psychological(e.g., concentrating activity), cognitive(e.g., goal setting and self-regulation), and behavioral (e.g., social involvement)(D'raven \& Pasha-Zaidi, 2016). Across several studies, engagement has been found to be positively associated with other indicators of well-being, including life satisfaction and positive emotion(Ruch, Harzer, Proyer, Park, \& Peterson, 2010; Vella-Brodrick, Park, \& Peterson, 2009).

The construct of relationships shows the ability that one can have positive relationships with others. It is the feelings of being cared about by other people, authentically connected to others, and secure in those connections(M. E. Seligman, 2012), which includes a sense of connectedness, loving, and sharing emotions with others. There is a positive correlation between positive relationships and academic achievements, as well as happiness(Diener \& Seligman, 2002; Pavot \& Diener, 2009; Peterson, 2006).

Meaning indicates that the individuals can have a sense of belonging and serve something they believe to be more meaningful than themselves, that is, a sense of purpose or fulfillment in life derived from something greater than the self(Butler \& Kern, 2016; M. E. Seligman, 2012; Steger, Kashdan, \& Oishi, 2008). People with a higher sense of meaning are proved to be with better physical and mental health, better academic achievement, along with higher life satisfaction(Brassai, Piko, \& Steger, 2011; Cavazos Vela, Castro, Cavazos, Cavazos, \& Gonzalez, 2015; DeWitz, Woolsey, \& Walsh, 2009; King, Hicks, Krull, \& Del Gaiso, 2006; Steger \& Frazier, 2005).

Accomplishment reveals that individuals can pursue personal goals and success, strive for, and achieve meaningful outcomes(Butler \& Kern, 2016; M. E. Seligman, 2012). The positive relationship has been proved between the positive accomplishment and school engagement and academic aspirations(Vasalampi, Salmela-Aro, \& Nurmi, 2009), mental flexibility and a growth 
mindset(Molden \& Dweck, 2006; Nussbaum \& Dweck, 2008), and also, better academic performance(Blackwell, Trzesniewski, \& Dweck, 2007; Mangels, Butterfield, Lamb, Good, \& Dweck, 2006).

Ample research available shows the evidence that the PERMA model has a positive influence on promoting students' psychological well-being(a sense of purpose and positive emotions) and their relationships, academic motivation, skills, and performance(Kern, Waters, Adler, \& White, 2015; Norrish \& Vella-Brodrick, 2009; Norrish, Williams, O'Connor, \& Robinson, 2013; Oades, Robinson, Green, \& Spence, 2011; M. Seligman, 2011; M. E. Seligman, 2012; M. E. Seligman, Ernst, Gillham, Reivich, \& Linkins, 2009; Shoshani, Steinmetz, \& KanatMaymon, 2016). Although Seligman(2012) proposed the PREMA model and some scholars(Allen, 2017; Joel, 2017) have proven PERMA as a valid, reliable, and practicable model among athletes, education leaders, soldiers, nurses, and service workers. However, the research on university and college students' psychology is generally sparse, even none in the field of second language acquisition and English foreign language learning. Also, the PERMA profile has few research results reported on university and college EFL students, there is still research missing in a non-diverse sample of EFL students.

Considering the general problem of language anxiety among Chinese college EFL students, there have been more and more voices calling for integrating positive psychology into this field(MacIntyre, Gregersen, \& Mercer, 2016), it is a need to have gradually gained entry into the language education field to determine the validity and reliability of the instrument adopted from Butler\&Kern(2016) to examine if the generally accepted instruments for PERMA model are truly universal in Chinese EFL context.

\section{Research questions}

1. Does the five-factor correlated structure of the PERMA model instrument optimally fit data in the Chinese EFL context?

2. Is the PERMA model instrument reliable and valid for measuring students' positive psychology in the Chinese EFL context?

\section{Research method}

Research design

This research applied quantitative methods. A quantitative method is a research design that explains phenomena by collecting numerical data that are analyzed using mathematically based methods, in particular, statistics to analyze the data(Aliaga \& Gunderson, 1999). That is to say, quantitative research is an approach for testing objective theories by examining the relationship among variables. These variables, in turn, can be measured, typically on instruments, so that numbered data can be analyzed using statistical procedures(Creswell \& Creswell, 2017). The current research adopts the survey research, which has great statistical power and a high degree of generalizability(Babbie, 2013; Creswell, 2014; Flick, 2015), can help the researcher identify the beliefs and attitudes of individuals(Creswell, 2008; Punch, 2013), and measure the phenomena which cannot be observed directly but do exist in the environment(Gall, Gall, \& Borg, 1999).

\section{Research subject}

Using probability sampling(Creswell \& Clark, 2017), the population of this particular research includes 309 Chinese university EFL students, which were employed from 10 universities in Gansu province. All selected universities adopt blended learning in EFL education. Ranging 
from 18 to 22 years old, targeted volunteers included 184(59.6\%) female and 125(40.4\%) male subjects. All participants answered the questionnaire during the EFL face-to-face lecture hours.

\section{Research instrument}

The current research adopts the 15-item PERMA questionnaire from Butler and Kern(2016). As an 11-point Likert-type scale, it includes five aspects, that is, positive emotions, engagement, relationship, meaning, and accomplishment. There are three items available in every construct. Back translation from experts in this field and pilot study in the Chinese context was utilized to ensure the validity and reliability of the instrument. Due to non-native speakers participants are, after the back translation of expert to ensure its comparability and precision, also, a pre-test was conducted on ten subjects to check and test its structure, wording, and the probable responding time. Then the pilot study is carried out and the SPSS version 24.0 was used in the analysis of the pilot study. The result of the pilot study shows that the PERMA profiler is reliable(Cronbach's Alpha of positive emotions is 0.836 , engagement is 0.872 , relationship is 0.966, meaning is 0.944, and accomplishment is 0.872.). Then the SPSS version 24.0 and the AMOS version 24.0 were employed in the actual study to conduct exploratory factor analysis(EFA) and confirmatory factor analysis(CFA) respectively in the Chinese context to answer the research questions in the present research.

\section{Research results}

Preliminary analysis

In the stage of the preliminary analysis, the missing data, outliers, and normality are checked for further data analysis. With the skewness and kurtosis value ranging from -1.96 to +1.96 at 0.05 significant level data analysis(Hair, Black, Babin, Anderson, \& Tatham, 1998), univariate normality of construct is identified carefully by this standard. The correlation of more than 0.90 is also regarded as multicollinearity(Kline, 2015). The means, standard deviations as well as correlation matrix, skewness, and kurtosis for all constructs are shown in Table 1.

Table 1 Descriptive statistics and inter-correlations of the variables.

\begin{tabular}{cccccc}
\hline Variables & 1 & 2 & 3 & 4 & 5 \\
\hline 1. Positive Emotions & 1 & $.481^{* *}$ & $.489^{* *}$ & $.464^{* *}$ & $.553^{* *}$ \\
2. Engagement & & 1 & $.425^{* *}$ & $.470^{* *}$ & $.456^{* *}$ \\
3.Relationship & & & 1 & $.474^{* *}$ & $.434^{* *}$ \\
4. Meaning & & & & 1 & $.448^{* *}$ \\
5. Accomplishment & & & & & 1 \\
Skew & -1.119 & -1.145 & -0.953 & -1.103 & -0.936 \\
Kurtosis & 0.020 & 0.083 & -0.393 & 0.172 & -0.369 \\
M & 6.249 & 6.448 & 6.147 & 6.493 & 6.182 \\
SD & 2.392 & 2.462 & 2.697 & 2.556 & 2.460 \\
\hline
\end{tabular}

Note: **Correlation is significant at the 0.01 level (two-tailed)

According to Table 1, the output of the preliminary analysis for the items of the PERMA model has achieved the standard of univariate normality(the skewness and kurtosis values ranging from -1.145 to 0.172 ). As to multicollinearity, the correlation value of each sub-constructs ranged from 0.425 to 0.553 , indicating that each sub-construct reached discriminant validities. 
In the instrument of the PERMA model, there are fifteen items available to measure five constructs, that is, positive emotions, engagement, relationship, meaning, and accomplishment, in which each construct has three items. The exploratory factor analysis was carried out by SPSS version 24.0 to check whether the statistical criteria were satisfied in the current study. The results of EFA show that the value of Kaiser-Meyer-Olkin (KMO) for PERMA was $0.883>0.70$, and the Bartlett Chi-square approximation was 3704.386 with $p=0.000$., which is significant, rejecting the null hypothesis that the correlation matrix was an identity matrix. All of these ensure the availability of an adequate number of items for each factor and provide evidence that the EFA method was appropriate for use in current research(Auerswald \& Moshagen, 2019). Therefore, the next step was to identify the values of the extraction communalities, eigenvalues, percentage of variances, and factor loading.

Table 2. Factor Loadings, Communalities, Eigenvalues, and Percentage of Variances For PERMA

\begin{tabular}{|c|c|c|c|c|c|c|c|c|c|c|}
\hline \multirow[t]{2}{*}{ Factor } & \multirow[t]{2}{*}{ Dimensions } & \multirow[t]{2}{*}{ Items } & \multirow[t]{2}{*}{ Communalities } & \multirow[t]{2}{*}{ Eigenvalue } & \multirow{2}{*}{$\begin{array}{c}\% \text { of } \\
\text { Variance }\end{array}$} & \multicolumn{5}{|c|}{ Components } \\
\hline & & & & & & 1 & 2 & 3 & 4 & 5 \\
\hline \multirow{15}{*}{ PERMA } & Positive & PE1 & 0.843 & 1.076 & 7.173 & 0.869 & & & & \\
\hline & Emotions & PF? & 0811 & & & 0794 & & & & \\
\hline & & PE3 & 0.727 & & & 0.693 & & & & \\
\hline & Engagement & E1 & 0.864 & 1.301 & 8.676 & & 0.867 & & & \\
\hline & & E2 & 0.742 & & & & 0.793 & & & \\
\hline & & E3 & 0.787 & & & & 0.824 & & & \\
\hline & Relationship & $\mathrm{R} 1$ & 0.933 & 7.233 & 48.217 & & & 0.902 & & \\
\hline & & $\mathrm{R} 2$ & 0.902 & & & & & 0.882 & & \\
\hline & & R3 & 0.909 & & & & & 0.883 & & \\
\hline & Meaning & M1 & 0.855 & 1.570 & 10.466 & & & & 0.825 & \\
\hline & & M2 & 0.840 & & & & & & 0.862 & \\
\hline & & M3 & 0.919 & & & & & & 0.895 & \\
\hline & Accomplishment & A1 & 0.803 & 1.458 & 9.723 & & & & & 0.819 \\
\hline & & $\mathrm{A} 2$ & 0.846 & & & & & & & 0.844 \\
\hline & & A3 & 0.857 & & & & & & & 0.865 \\
\hline
\end{tabular}

Table 2 presents the detail of factor loading, communalities, eigenvalues, and the percentage of variances explained by the sub-constructs of PERMA.

Firstly, the values of the extraction communalities represent the variance in each item calculated before and after the factor analysis. The values of such communalities for each item which were less than 0.50 were dropped from further analysis(Hair, Black, Babin, Anderson, \& Tatham, 2006). Small values $(<0.50)$ of the extraction communalities indicate that less than half of the variance in the item was considered in identifying the latent construct. In the current research, all item communalities ranged from 0.727 to 0.933 , which exceeded the 0.50 level for adequate explanation.

Next, a five-factor solution with eigenvalues over 1 emerged from the EFA, explaining $84.26 \%$ of the variance in total. The PERMA factors and their contributions were as follows: relationship, 48.22\%; meaning, 10.47\%; accomplishment, 9.72\%; engagement, 8.68\%; and 
positive emotions, $7.17 \%$. The component matrix after varimax rotation was employed to identify the items that were more related to each factor. In the present study, all suggested 15 items for measuring PERMA were registered by high loading factors ranging from 0.693 to $0.902(>0.50)$.

Another method to select the correct number of factors to be extracted is to investigate a scree plot (Figure 1). As shown in Figure 1, the scree plot suggests five factors that can be determined.

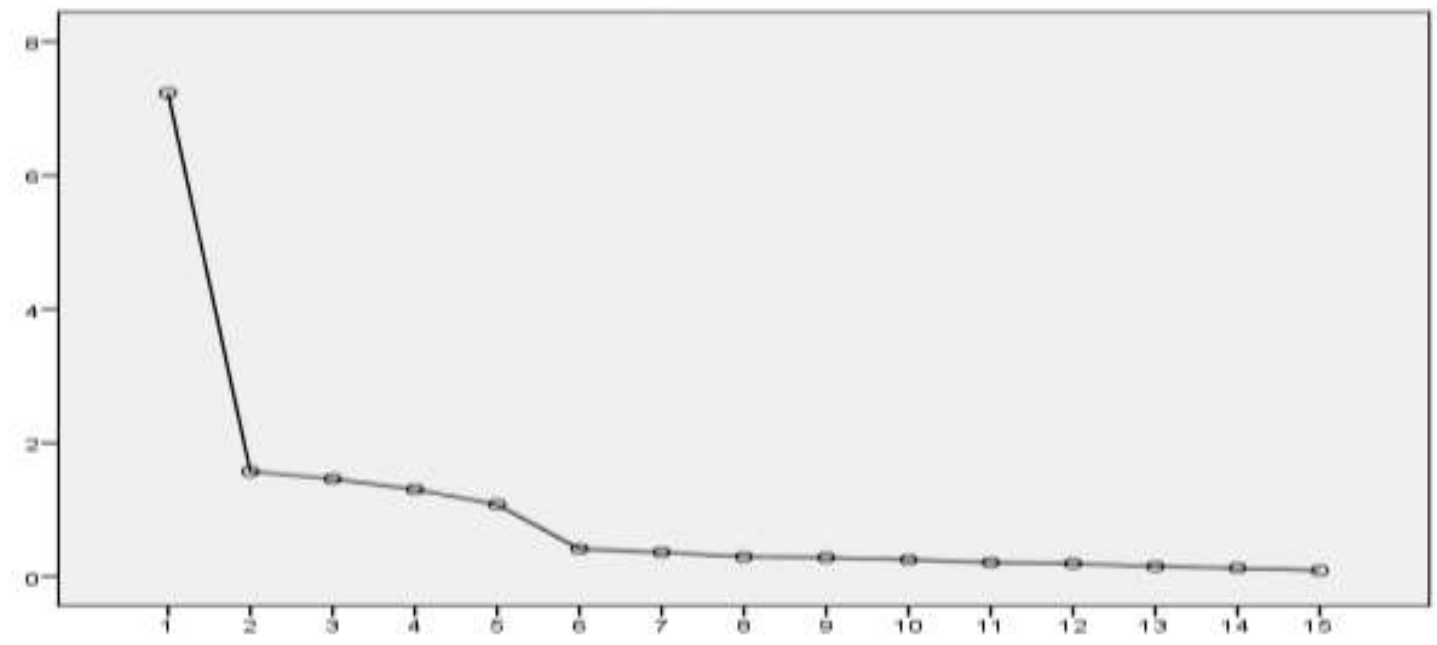

Figure 1. Scree plot of the 15 items for PERMA

Confirmatory factor analysis: testing the measurement models.

Among the available quantitative methods, the CFA always be carried out in order to verify the construct validity of the instrument developed(Campbell \& Fiske, 1959; Hoyle, 2012; Kline, 1998). It is the main advantage of CFA in construct validity research that directly comparing alternative models of relationships among constructs is possible and achievable(Whitely, 1983). With the extensive use of CFA, the validity of the construct can be assessed by AMOS software(Kline, 2015). Through CFA, the questionnaire can be revised as a better instrument based on the outcome generated from the construct validity.

Therefore, after the EFA analysis in the present research, the confirmatory factor analysis(CFA) was conducted by AMOS version 24.0 to verify the factorial validity(Awang, Afthanorhan, \& Mamat, 2016) of the PERMA instrument. The models were compared using chisquare $(\chi 2), \chi 2 / \mathrm{df}, \mathrm{GFI}, \mathrm{AGFI}, \mathrm{CFI}, \mathrm{TLI}$, and RMSEA. Table 3 presents the model specifications for CFA.

Table 3. Model Specifications for the Confirmatory Factor Analysis

\begin{tabular}{cc}
\hline Parameter & Coefficient \\
\hline$\chi^{2}$ & 123.953 \\
$\chi 2 / \mathrm{df}$ & 1.549 \\
GFI & 0.951 \\
AGFI & 0.927 \\
CFI & 0.988 \\
TLI & 0.984 \\
RMSEA & 0.042 \\
\hline
\end{tabular}


Note. $\chi 2$ : Chi-square goodness of fit; df: Degrees of Freedom; GFI: Goodness-of-Fit Index; AGFI: Adjusted Goodness-of-Fit Index; CFI: Comparative Fit Index; TLI: Tucker Lewis Index; RMSEA: Root Mean Square Error of Approximation

Table 3 illustrates that the CFA results using AMOS version 24.0 for the hypothesized fivefactor model are excellent. The model fit of the hypothetical PERMA model was considered acceptable in the Chinese context, which show that $\chi^{2}=123.953, \chi 2 / \mathrm{df}=1.549$, GFI $=0.951$, $\mathrm{AGFI}=0.927, \mathrm{CFI}=0.988$, and RMSEA $=0.042$. Therefore, the model of CFA presented in Figure 2 is the finalized measurement model that indicated the structure of PERMA in the Chinese context

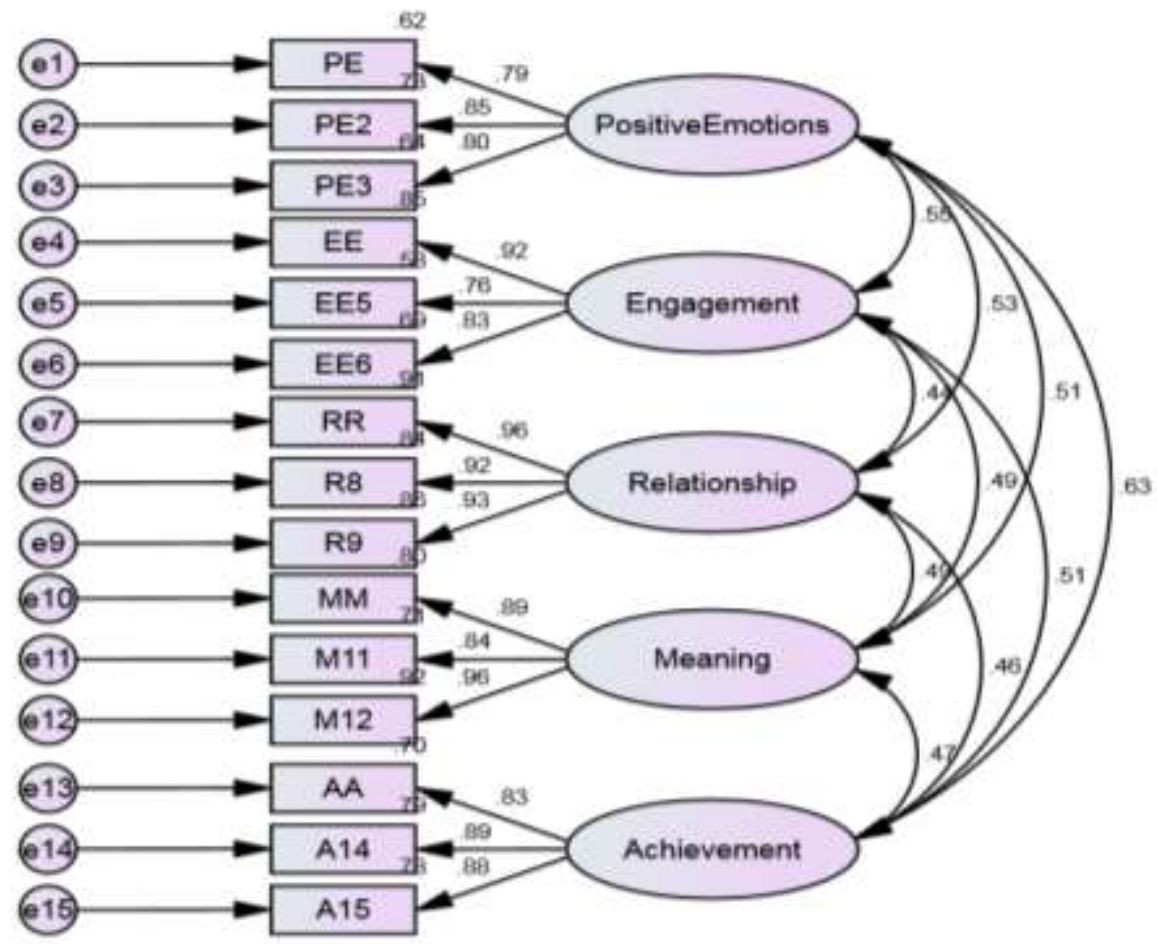

Figure 2. The finalized measurement model of CFA

Figure 2 shows that the finalized measurement model of PERMA. Ranging from 0.76 to 0.96, all factor loadings of the five PERMA' sub-constructs exceeded the desirable standard of 0.50(Hair et al., 1998), which is considered acceptable convergent validity. As to discriminant validity, the correlations among the five PERMA' sub-constructs ranged from 0.44 to 0.63 , which are considered acceptable discriminant validity. This finalized model became the baseline model for our next analyses related to cross-validation.

Confirmatory factor analysis: testing of a second-order factor

The current research also hypothesized and examined the second-order factorial structure for the PERMA model. The second-order latent variables can be situated as an explanatory variable to an endogenous variable, namely, positive emotions, engagement, relationship, meaning, and accomplishment. Figure 3 displays the results of the hypothesized second-order factorial structure for the PERMA model. According to Figure 3, the path coefficients for PERMA in the hierarchical model varied among sub-constructs: positive emotions(0.80), engagement (0.69), relationship (0.66), meaning (0.67), and accomplishment (0.73), which are considered acceptable. 


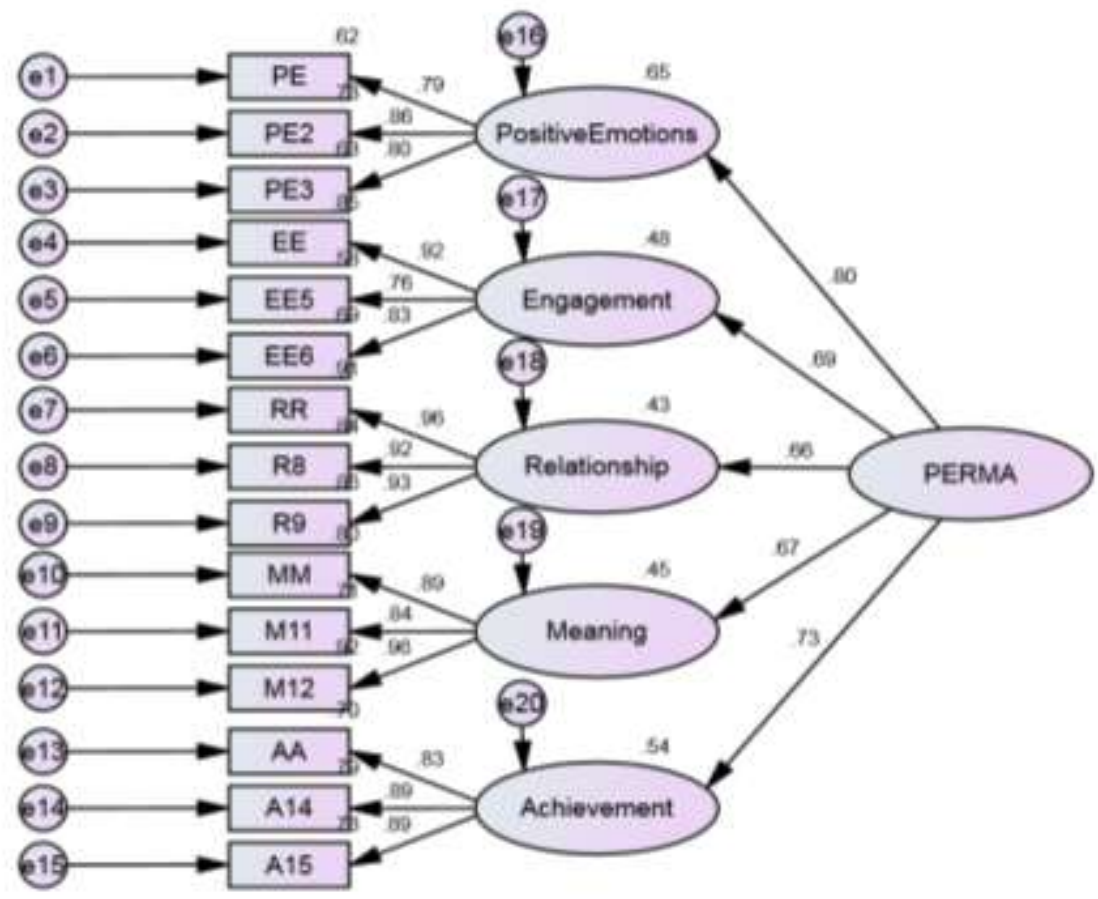

Figure 2. A second-order measurement model for PERMA

For comparison, the model fit statistics of the first- and second-order measurement models for PERMA are listed in Table 4. A second-order measurement model for PERMA also indicated acceptable model fit, $\chi 2=129.699, \chi 2 / \mathrm{df}=1.526, \mathrm{GFI}=0.949, \mathrm{AGFI}=0.929, \mathrm{CFI}=0.988$, TLI $=0.985$, RMSEA $=0.041$.

Table 4. Model fit statistics for each hypothesized factor model

\begin{tabular}{cccccccc}
\hline Model & $\chi^{2}$ & $\chi^{2 / \mathrm{df}}$ & GFI & AGFI & CFI & TLI & RMSEA \\
\hline First-order & 123.953 & 1.549 & 0.951 & 0.927 & 0.988 & 0.984 & 0.042 \\
Second-order & 129.699 & 1.526 & 0.949 & 0.929 & 0.988 & 0.985 & 0.041 \\
\hline
\end{tabular}

Reliability of the PERMA-profiler scales

Once the CFA was finished, the instrument of the PERMA model was confirmed in 15 items(Appendix A). Then the reliability of the PERMA instrument was considered. Reliability refers to the stability and consistency of the scores obtained(Creswell, 2014; Fraenkel, Wallen, \& Hyun, 2011). In the current study, the internal consistency test(Cronbach's Alpha), construct reliability (CR) and AVE were calculated. The value of Cronbach's Alpha higher than 0.70 was considered acceptable(Lim, 2007). Also, CR should be more than 0.60 and AVE must be over 0.50(Awang et al., 2016). Table 5 shows the Cronbach's Alpha, CR, and AVE for the subconstructs of PERMA. 
Table 5. Reliability analysis for PERMA

\begin{tabular}{ccccc}
\hline \multirow{2}{*}{ Construct } & Sub-Construct & Alpha & CR & \multirow{2}{*}{ AVE } \\
\hline \multirow{4}{*}{ PERMA } & Positive Emotions & 0.853 & 0.855 & 0.663 \\
& Engagement & 0.871 & 0.877 & 0.705 \\
& Relationship & 0.953 & 0.953 & 0.872 \\
& Meaning & 0.924 & 0.928 & 0.81 \\
& Accomplishment & 0.902 & 0.902 & 0.755 \\
\hline
\end{tabular}

As is shown in Table 5, the Cronbach's Alpha of each sub-construct exceeded the desirable standard of 0.70: positive emotions, $\alpha=0.853$; engagement, $\alpha=0.871$; relationship, $\alpha=0.953$; meaning, $\alpha=0.924$ and accomplishment, $\alpha=0.902$. Meanwhile, all the CR values for the subconstructs of PERMA exceeded the desirable standard of 0.60 , which indicated high internal consistency. Moreover, the AVE for the five latent variables exceeded the common cut-off value of 0.50 , demonstrating that this research had acceptable discriminant validity.

\section{Discussion}

Based on the results of the research that has been analyzed above, the PERMA profiler is of acceptable reliability and validity to evaluate the positive psychology of Chinese university EFL students. Aiming at exploring the reliability and the validity of the PERMA instrument for Chinese undergraduates in EFL learning, the result of present research in EFA shows that there are five constructs available in the PERMA model, that is, positive emotions, engagement, relationship, meaning, and accomplishment. This structure coincides with the original PERMA framework, which is also in line with the previous research in other contexts(Arvig, 2006; Baltzell, Akhtar, McCarthy, Hurley, \& Martin, 2014; Bartholomaeus, Iasiello, Jarden, Burke, \& van Agteren, 2020; Coffey, Wray-Lake, Mashek, \& Branand, 2016; Diener et al., 2010; Dimitropoulou \& Leontopoulou, 2017; Kern, Waters, Adler, \& White, 2014; Kern et al., 2015; Leontopoulou, 2020; Pezirkianidis, Stalikas, Lakioti, \& Yotsidi, 2019; Umucu et al., 2020). Furthermore, in the present study, the factor structure for the Chinese EFL university students was identified by both EFA and CFA analysis. The result of CFA indicated the suitability of the PERMA profiler to measure the level of positive psychology. Also, the reliability and validity analysis of all the sub-constructs are also satisfactory, which provides evidence that the PERMA instrument is universal and acceptable. The outcome concludes that this instrument can measure the level of positive psychology perceived by Chinese EFL undergraduates, and, therefore, researchers can rely on its use.

\section{Conclusion}

The purpose of this research is to verify the PERMA profiler to evaluate the positive psychology of Chinese university EFL students. On the basis of the present research, it can be concluded that the PERMA scale, although new, may be useful for researchers in the field of positive psychology and educational psychology. The validated survey can help teachers better understand university students' emotions and monitor their EFL learning. Researchers can use it to know the real situation of undergraduates and design educational interventions or provide policy suggestions based on research results. All of these are essential to boost the quality of EFL learning and students' positive psychology. Therefore, the outcomes of this research enlighten the influence of positive psychology and determine the nature of PERMA for Chinese university EFL students. Declaration of conflicting interest 
The authors state that there is no conflict of interest concerning the publication of this article.

Funding acknowledgement

This research received no external funding.

\section{References}

Aliaga, M., \& Gunderson, B. (1999). Interactive statistics: Prentice Hall.

Allen, K. M. (2017). The Effect of Participation in PERMA Plus Yoga on Salutogenic Wellness and Flourishing in People over Age 50: AT Still University of Health Sciences.

Arvig, T. (2006). Meaning in life for individuals with physical disabilities. Psychological reports, 98(3), 683-688.

Auerswald, M., \& Moshagen, M. (2019). How to determine the number of factors to retain in exploratory factor analysis: A comparison of extraction methods under realistic conditions. Psychological methods, 24(4), 468.

Awang, Z., Afthanorhan, A., \& Mamat, M. (2016). The Likert scale analysis using parametric based Structural Equation Modeling (SEM). Computational Methods in Social Sciences, 4(1), 13.

Babbie, E. R. (2013). The basics of social research: Cengage learning.

Baltzell, A., Akhtar, V. L., McCarthy, J., Hurley, D., \& Martin, I. (2014). Happiness and well-being models: Empirical support from high school coaching study. Athletic Insight, 6(2), 125.

Bartholomaeus, J. D., Iasiello, M. P., Jarden, A., Burke, K. J., \& van Agteren, J. (2020). Evaluating the Psychometric Properties of the PERMA Profiler. Journal of Well-Being Assessment, 4(2), 163180.

Blackwell, L. S., Trzesniewski, K. H., \& Dweck, C. S. (2007). Implicit theories of intelligence predict achievement across an adolescent transition: A longitudinal study and an intervention. Child development, 78(1), 246-263.

Brassai, L., Piko, B. F., \& Steger, M. F. (2011). Meaning in life: Is it a protective factor for adolescents' psychological health? International journal of behavioral medicine, 18(1), 44-51.

Butler, J., \& Kern, M. L. (2016). The PERMA-Profiler: A brief multidimensional measure of flourishing. International Journal of Wellbeing, 6(3).

Campbell, D. T., \& Fiske, D. W. (1959). Convergent and discriminant validation by the multitraitmultimethod matrix. Psychological bulletin, 56(2), 81.

Cavazos Vela, J., Castro, V., Cavazos, L., Cavazos, M., \& Gonzalez, S. L. (2015). Understanding Latina/o students' meaning in life, spirituality, and subjective happiness. Journal of Hispanic Higher Education, 14(2), 171-184.

Coffey, J. K. (2018). Positive Psychology of Infancy and Early Childhood: Chapter in the Handbook of Positive Psychology.

Coffey, J. K., Warren, M. T., \& Gottfried, A. W. (2015). Does infant happiness forecast adult life satisfaction? Examining subjective well-being in the first quarter century of life. Journal of Happiness Studies, 16(6), 1401-1421.

Coffey, J. K., Wray-Lake, L., Mashek, D., \& Branand, B. (2016). A multi-study examination of wellbeing theory in college and community samples. Journal of Happiness Studies, 17(1), 187-211.

Cohn, M. A., \& Fredrickson, B. L. (2009). Positive emotions. Oxford handbook of positive psychology, 2, 13-24.

Creswell, J. W. (2008). Qualitative, quantitative, and mixed methods approaches.

Creswell, J. W. (2014). Research design: qualitative, quantitative, and mixed methods approaches.

Creswell, J. W., \& Clark, V. L. P. (2017). Designing and conducting mixed methods research: Sage publications.

Creswell, J. W., \& Creswell, J. D. (2017). Research design: Qualitative, quantitative, and mixed 
methods approaches: Sage publications.

Csikszentmihalyi, M., Abuhamdeh, S., \& Nakamura, J. (1990). Flow: New York: Harper \& Row.

D'raven, L. L., \& Pasha-Zaidi, N. (2016). Using the PERMA model in the United Arab Emirates. Social indicators research, 125(3), 905-933.

DeWitz, S. J., Woolsey, M. L., \& Walsh, W. B. (2009). College student retention: An exploration of the relationship between self-efficacy beliefs and purpose in life among college students. Journal of college student development, 50(1), 19-34.

Diener, E. (2000). Subjective well-being: The science of happiness and a proposal for a national index. American psychologist, 55(1), 34.

Diener, E., \& Seligman, M. E. (2002). Very happy people. Psychological science, 13(1), 81-84.

Diener, E., Wirtz, D., Tov, W., Kim-Prieto, C., Choi, D.-w., Oishi, S., \& Biswas-Diener, R. (2010). New well-being measures: Short scales to assess flourishing and positive and negative feelings. Social indicators research, 97(2), 143-156.

Dimitropoulou, C., \& Leontopoulou, S. (2017). A positive psychological intervention to promote wellbeing in a multicultural school setting in Greece.

Flick, U. (2015). Introducing research methodology: A beginner's guide to doing a research project: Sage.

Fraenkel, J., Wallen, N., \& Hyun, H. (2011). Validity and reliability, how to design and evaluate research in science education: Mc Graw-Hill Companies.

Gable, S. L., \& Haidt, J. (2005). What (and why) is positive psychology? Review of general psychology, 9(2), 103-110.

Gall, J. P., Gall, M. D., \& Borg, W. R. (1999). Applying educational research: A practical guide: Longman Publishing Group.

Hair, J. F., Black, W. C., Babin, B. J., Anderson, R. E., \& Tatham, R. (2006). Multivariate data analysis . Uppersaddle River: NJ: Pearson Prentice Hall.

Hair, J. F., Black, W. C., Babin, B. J., Anderson, R. E., \& Tatham, R. L. (1998). Multivariate data analysis (Vol. 5): Prentice hall Upper Saddle River, NJ.

Hoyle, R. H. (2012). Handbook of structural equation modeling: Guilford press.

Joel, D. (2017). Job Satisfaction Levels Among Iowa Public School Superintendents. Drake University.

Kern, M. L., Waters, L., Adler, A., \& White, M. (2014). Assessing employee wellbeing in schools using a multifaceted approach: Associations with physical health, life satisfaction, and professional thriving.

Kern, M. L., Waters, L. E., Adler, A., \& White, M. A. (2015). A multidimensional approach to measuring well-being in students: Application of the PERMA framework. The journal of positive psychology, 10(3), 262-271.

King, L. A., Hicks, J. A., Krull, J. L., \& Del Gaiso, A. K. (2006). Positive affect and the experience of meaning in life. Journal of personality and social psychology, 90(1), 179.

Kline, R. B. (1998). Structural equation modeling. New York: Guilford.

Kline, R. B. (2015). Principles and practice of structural equation modeling: Guilford publications.

Leontopoulou, S. (2020). Measuring well-being in emerging adults: Exploring the PERMA framework for positive youth development. Psychology: the Journal of the Hellenic Psychological Society, 25(1), 72-93.

Lim, H. L. (2007). Community of inquiry in an online undergraduate information technology course. Journal of Information Technology Education: Research, 6(1), 153-168.

MacIntyre, P. D., Gregersen, T., \& Mercer, S. (2016). Positive psychology in SLA: Multilingual Matters.

Mangels, J. A., Butterfield, B., Lamb, J., Good, C., \& Dweck, C. S. (2006). Why do beliefs about intelligence influence learning success? A social cognitive neuroscience model. Social cognitive and affective neuroscience, 1(2), 75-86.

Molden, D. C., \& Dweck, C. S. (2006). Finding" meaning" in psychology: a lay theories approach to 
self-regulation, social perception, and social development. American psychologist, 61(3), 192.

Norrish, J. M., \& Vella-Brodrick, D. A. (2009). Positive psychology and adolescents: Where are we now? Where to from here? Australian Psychologist, 44(4), 270-278.

Norrish, J. M., Williams, P., O'Connor, M., \& Robinson, J. (2013). An applied framework for positive education. International Journal of Wellbeing, 3(2).

Nussbaum, A. D., \& Dweck, C. S. (2008). Defensiveness versus remediation: Self-theories and modes of self-esteem maintenance. Personality and Social Psychology Bulletin, 34(5), 599-612.

Oades, L. G., Robinson, P., Green, S., \& Spence, G. B. (2011). Towards a positive university. The Journal of Positive Psychology, 6(6), 432-439.

Pavot, W., \& Diener, E. (2009). Review of the satisfaction with life scale Assessing well-being (pp. 101-117): Springer.

Peterson, C. (2006). A primer in positive psychology: Oxford university press.

Pezirkianidis, C., Stalikas, A., Lakioti, A., \& Yotsidi, V. (2019). Validating a multidimensional measure of wellbeing in Greece: Translation, factor structure, and measurement invariance of the PERMA Profiler. Current Psychology, 1-18.

Punch, K. F. (2013). Introduction to social research: Quantitative and qualitative approaches: sage.

Ruch, W., Harzer, C., Proyer, R. T., Park, N., \& Peterson, C. (2010). Ways to happiness in Germanspeaking countries. European Journal of Psychological Assessment.

Seligman, M. (2011). Flourish: a visionary new understanding of happiness and well-being. Policy, 27(3), 60-61.

Seligman, M. E. (2012). Flourish: A visionary new understanding of happiness and well-being: Simon and Schuster.

Seligman, M. E., \& Csikszentmihalyi, M. (2000). Positive Psychology.

Seligman, M. E., Ernst, R. M., Gillham, J., Reivich, K., \& Linkins, M. (2009). Positive education: Positive psychology and classroom interventions. Oxford review of education, 35(3), 293-311.

Shoshani, A., Steinmetz, S., \& Kanat-Maymon, Y. (2016). Effects of the Maytiv positive psychology school program on early adolescents' well-being, engagement, and achievement. Journal of school psychology, 57, 73-92.

Snyder, C. R., \& Lopez, S. J. (2009). Oxford handbook of positive psychology: Oxford library of psychology.

Steger, M. F., \& Frazier, P. (2005). Meaning in life: One link in the chain from religiousness to wellbeing. Journal of Counseling Psychology, 52(4), 574.

Steger, M. F., Kashdan, T. B., \& Oishi, S. (2008). Being good by doing good: Daily eudaimonic activity and well-being. Journal of Research in Personality, 42(1), 22-42.

Umucu, E., Wu, J.-R., Sanchez, J., Brooks, J. M., Chiu, C.-Y., Tu, W.-M., \& Chan, F. (2020). Psychometric validation of the PERMA-profiler as a well-being measure for student veterans. Journal of American college health, 68(3), 271-277.

Vasalampi, K., Salmela-Aro, K., \& Nurmi, J.-E. (2009). Adolescents' self-concordance, school engagement, and burnout predict their educational trajectories. European psychologist, 14(4), 332-341.

Vella-Brodrick, D. A., Park, N., \& Peterson, C. (2009). Three ways to be happy: Pleasure, engagement, and meaning-Findings from Australian and US samples. Social indicators research, 90(2), 165-179.

Wesson, K., \& Boniwell, I. (2007). Flow theory-its application to coaching psychology. International Coaching Psychology Review, 2(1), 33-43.

Whitely, S. E. (1983). Construct validity: Construct representation versus nomothetic span. Psychological bulletin, 93(1), 179. 